\title{
Aerosol Containment Box
}

\author{
Yellamanchali Sreenivas Rao ${ }^{1}$ · Sayam Rajeshwar Rao ${ }^{1}[$
}

Received: 8 May 2020 / Revised: 15 June 2020 / Accepted: 20 June 2020 / Published online: 3 July 2020

(C) Indian National Academy of Engineering 2020

\begin{abstract}
In the pandemic situation created by COVID-19, which is a fast spreading human-to-human transmittable disease, it is essential to protect health care providers. They are frontline warriors who fight this disease by treating patients and are most vulnerable to the same disease. In the current scenario, it is required to come up with innovative solutions to protect health care providers, such innovations should be made in to usable products with limited resources available due to lock down condition prevailing in the market and should be provided to them instantly. Main routes of infection of COVID-19 disease are, direct contact with objects that has virus on it and indirect contact by inhaling droplets emitted through sneezes and cough of patients. Healthcare providers can avoid direct contact with objects having virus by using proper PPE (Personal Protective Equipment). However, they are at risk of transmissions by microscopic aerosol particles consisting of the residual solid components of evaporated respiratory droplets, which are tiny enough $(<5 \mu \mathrm{m})$ to remain airborne for hours created by cough and sneeze. Authors have come with such a solution, called as 'Aerosol Containment Box' that act as barrier to safeguard health care providers from viral infection while performing medical procedures. It is made of transparent acrylic box, and covers COVID-19 patient from head up to chest. This box has to be placed on the body of the patient while he is being treated. This box is of low cost, can be made easily with limited resources and can be re-used after disinfection. This box is conceptualized, designed, manufactured, engineered and demonstrated within a record duration of 3 days. 100 nos of such boxes are made within 15 days and are distributed at various hospitals in Hyderabad. Engineering drawings and manufacturing process are documented and shared with outstation enthusiastic manufacturers.
\end{abstract}

Keywords COVID-19 Aerosol containment $\cdot$ Protection to health care providers $\cdot$ Low cost solution

\section{Introduction}

On 30 January 2020, the World Health Organization (WHO) declared a global public health emergency and officially named the disease as the Coronavirus Disease 2019 (COVID-19). The rapidly spreading, highly contagious and pathogenic SARS-coronavirus 2 (SARS-CoV-2) are transmitted human-to-human has been confirmed by WHO and has continuously spread to 200 countries.

Corona virus disease 2019, caused by the SARS-CoV-2 virus, was first detected in Wuhan, China, in December 2019. Based on the available evidence, the COVID-19 virus is transmitted between people through close contact and droplets. The people most at risk of infection are those who

Sayam Rajeshwar Rao

sayam.rajeshwarrao@gmail.com

1 Programme 'AD', Defence Research and Development Organisation, Kanchanbagh P.O., Hyderabad 500058, India are in close contact with a COVID-19 patients or those who care for COVID-19 patients.

Asadi and team (2020), explained the role of aerosols in transmission of COVID 19 published in Aerosol Science and Technology journal. They described two possible modes of COVID 19 aerosols transmission; (1) during a sneeze or a cough, 'droplet sprays' of virus-laden respiratory tract fluid, typically greater than $5 \mu \mathrm{m}$ in diameter, impact directly on a susceptible individual and (2) alternatively, a susceptible person can inhale microscopic aerosol particles consisting of the residual solid components of evaporated respiratory droplets, which are tiny enough $(<5 \mu \mathrm{m})$ to remain airborne for hours. These droplets can potentially contaminate gown, gloves, face mask, eye shield and shoes also the floor of the hospital.

Aerosol Containment Box, which consists of a transparent acrylic cube designed to cover a patient's head and that incorporates two circular ports through which the clinician's hands are passed to perform the airway 


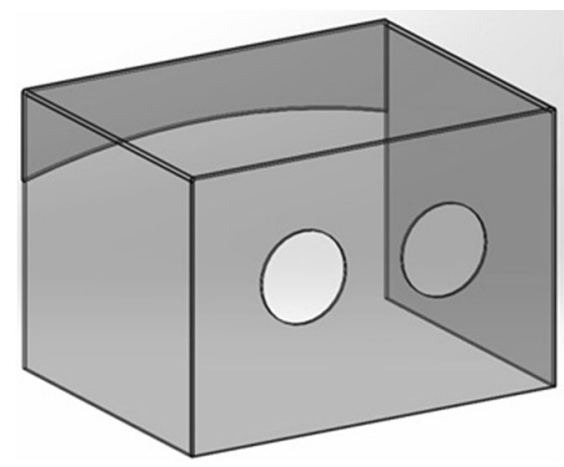

Fig. 1 Adult Aerosol Containment Box. Size: $650 \times 500 \times 450 \mathrm{~mm}$. Thickness sheet: $5 \mathrm{~mm}$

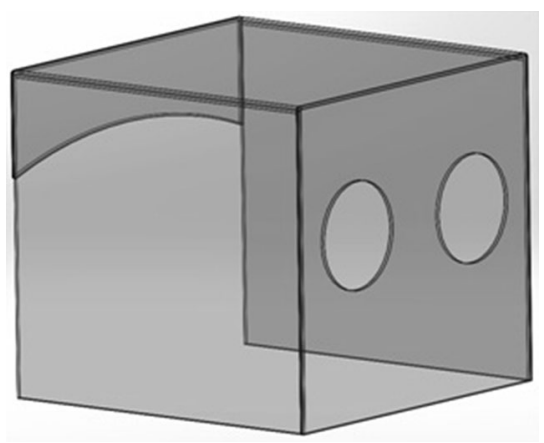

Fig. 2 Child Aerosol Containment Box. Size: $500 \times 500 \times 450 \mathrm{~mm}$. Thickness sheet: $5 \mathrm{~mm}$

procedure. This casing is half-covered till the patient's chest for not transmitting the droplets of patients while giving treatment. This Aerosol Box acts as barrier to safeguard health care provider while performing medical procedures. This Aerosol Box can be used while taking samples from a suspected patient, during intubation, observation or during treatment to completely avoid droplets, aerosols emanating from them due to cough and sneeze. Two sizes of Aerosol Box are designed and developed by authors for use by adult patients and child patients (Figs. 1,2).

\section{Advantages of Acrylic Material}

- Acrylic is transparent thermoset plastic material and it maintains transparency with time.

- Acrylic sheets are available in market.

- Low cost.

- It can be cut easily with home tools. It can be bent when heated and it retains shape when cooled.

\section{Technical Specifications of Acrylic Material}

- General properties: Relative density $1.19 \mathrm{~g} / \mathrm{cm}^{3}$, Rockwell hardness M 102.

- Flammability class 3, (BS 476 pt 7) UL94 HB.

- Tensile strength $75 \mathrm{MPa}$, Flexural strength $115 \mathrm{MPa}$.

- Minimum service temperature: $-40{ }^{\circ} \mathrm{C}$, Maximum service temperature: $80^{\circ} \mathrm{C}$.

- Softening point $>110^{\circ} \mathrm{C}$, Co-efficient of linear expansion: $7.7 \times 10^{-5}$.

- Optical properties: light transmission $>92 \%$, Refractive index 1.49.

\section{Disinfection of Aerosol Containment Box}

Aerosol Containment Box can be re-used after disinfection. Proper care should be taken during disinfection without which there is potential harm. Procedure for disinfection is as follows:

1. Abundantly spray $1 \%$ hypochlorite solution on internal and external surface of the box and leave it for $5 \mathrm{~min}$.

2. Repeat spraying $70 \%$ iso-propyl alcohol solution and keep it under UV-C lighting for drying for about $10-15$ min.

After the above procedure, the box can be re-used.

\section{Results and Discussion}

Aerosol Containment, which acts a physical barrier between COVID-19 patient and health care provider, acts as a protective equipment by containing aerosols and droplet created by cough and sneeze of a patient. Port openings provided in this transparent box enable intubation procedures.

Prototype units are manufactured and a demonstration is carried out by a team of doctors at ESI Medical College, Hyderabad and the design is validated and accepted (Fig. 3).

\section{Conclusion}

Health care providers who are treating COVID-19 patients are vulnerable to transmission of the same disease. Authors have provided a low cost solution named as Aerosol Containment Box to protect them during intubation procedure, sample collection and treatment of patients. The proto unit 
Fig. 3 Demonstration of intubation on a dummy at ESI Medical College, Hyderabad
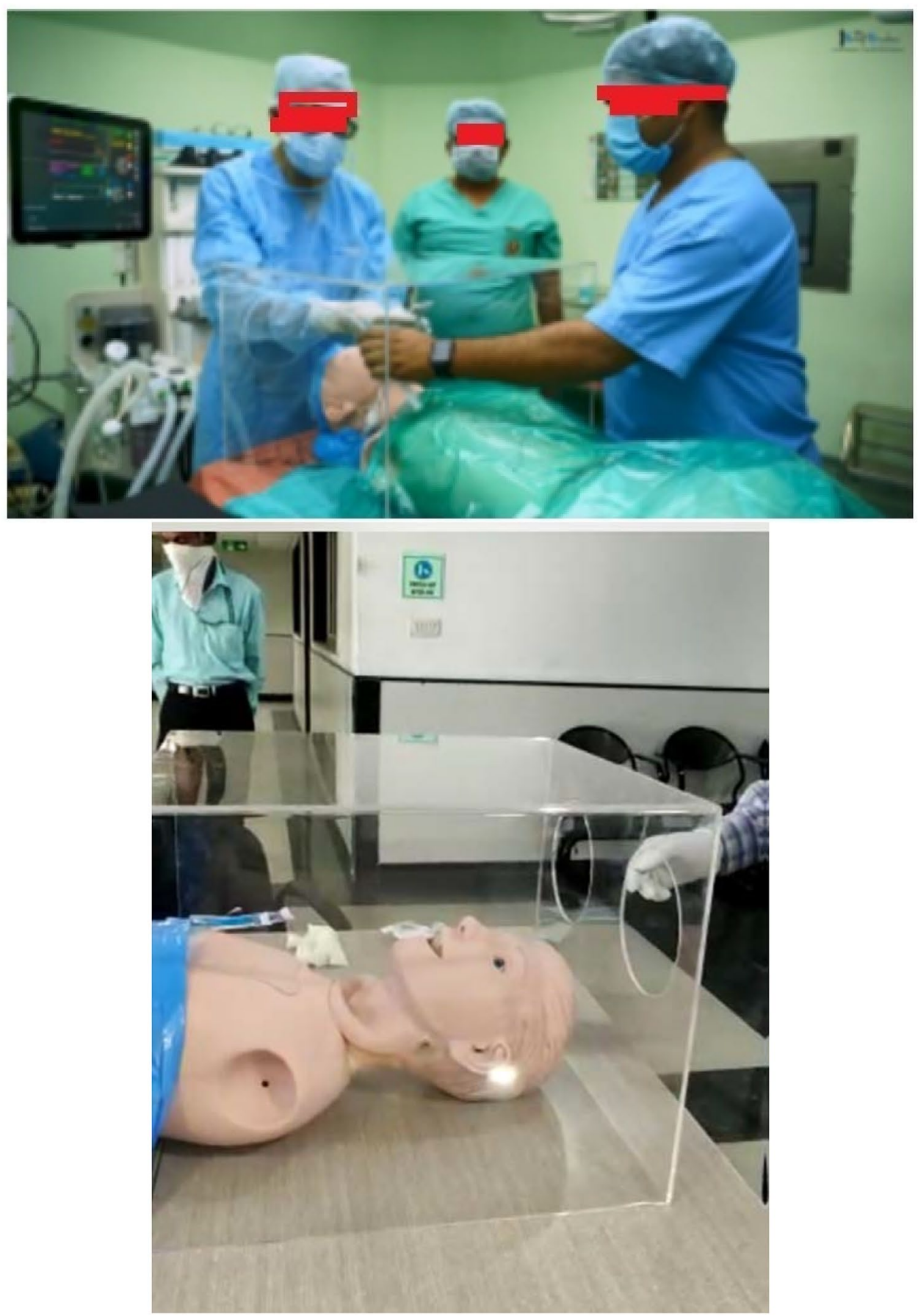

particles? Aerosol Sci Technol. https://doi.org/10.1080/02786 826.2020 .1749229

Publisher's Note Springer Nature remains neutral with regard to jurisdictional claims in published maps and institutional affiliations.

\section{Reference}

Asadi S, Bouvier N, Wexler AS, Ristenpart WD (2020) The coronavirus pandemic and aerosols: does COVID-19 transmit via expiratory 